\title{
Polymorphisms in GC and NADSYN1 Genes are associated with vitamin $D$ status and metabolic profile in Non-diabetic adults
}

Lydia Foucan ${ }^{1,2,9^{*}}$, Fritz-Line Vélayoudom-Céphise ${ }^{1,3}$, Laurent Larifla', Christophe Armand ${ }^{1}$, Jacqueline Deloumeaux ${ }^{1}$, Cedric Fagour ${ }^{1}$, Jean Plumasseau ${ }^{4}$, Marie-Line Portlis ${ }^{5}$, Longjian Liu $^{6}$, Fabrice Bonnet ${ }^{7}$ and Jacques Ducros ${ }^{8}$

\begin{abstract}
Background: Our aim was to assess the associations between vitamin D (vitD) status, metabolic profile and polymorphisms in genes involved in the transport (Group-Component: GC) and the hydroxylation (NAD synthetase 1: NADSYN1) of 25 hydroxyvitamin D (25(OH)D) in non-diabetic individuals.

Methods: We conducted a cross-sectional study with 323 individuals recruited from the Health Center of Guadeloupe, France. The rs2282679 T > G and rs2298849 T > C in GC and rs12785878 G > T in NADSYN1 were genotyped.

Results: Mean age was 46(range 18-86) years. 57\% of participants had vitD insufficiency, $8 \%$ had vitD deficiency, $61 \%$ were overweight and $58 \%$ had dyslipidemia. A higher frequency of overweight was noted in women carrying rs2298849T allele $v$ CC carriers (71\% $\vee 50 \%$; $P=0.035)$. The rs2282679G allele was associated with increased risks of vitD deficiency and vitD insufficiency ( $O R=3.53, P=0.008, O R=2.34, P=0.02$ respectively). The rs $2298849 \pi$ genotype was associated with vitD deficiency and overweight $(\mathrm{OR}=3.4, P=0.004$ and $\mathrm{OR}=1.76, P=0.04$ respectively) and the rs 12785878 GG genotype with vitD insufficiency and dyslipidemia (OR $=1.80, P=0.01$ and $\mathrm{OR}=1.72, P=0.03$ respectively). Based on the number of risk alleles for rs2282679 and rs12785878 combined, a genotype score of 3 (vs. 0-1) was associated with a $5.5 \mathrm{ng} / \mathrm{mL}$ average reduction in serum 25(OH)D levels $(P=0.001)$.
\end{abstract}

Conclusions: The GC and NADSYN1 genes are associated with the vitamin D status and might contribute to dyslipidemia and overweight independently of 25(OH)D levels.

Keywords: Dyslipidemia, Overweight, Vitamin D, NAD synthetase 1, NADSYN, Group specific component, GC

\section{Background}

The storage form of vitamin D, 25-hydroxyvitamin D $(25(\mathrm{OH}) \mathrm{D})$, measured in blood circulation is a marker of vitamin D status. Low $25(\mathrm{OH}) \mathrm{D}$ has been associated with increased risk of cardio-metabolic diseases, including obesity [1], dyslipidemia [2], type 2 diabetes [3], and cardiovascular complications $[2,4]$. However, genetic factors may also have effects on these diseases. In

\footnotetext{
* Correspondence: Ifoucan@yahoo.fr

${ }^{1}$ Research group Clinical Epidemiology and MedicineResearch group,

University of Antilles and Guyane, Guyane, France

${ }^{2}$ Department of Public Health and Medical Information, University Hospital of

Pointe-à-Pitre, Guadeloupe, France

Full list of author information is available at the end of the article
}

particular, single-nucleotide polymorphisms (SNPs) in genes of the vitamin $\mathrm{D}$ pathway that are involved in the transport or the hydroxylation of $25(\mathrm{OH}) \mathrm{D}$ may be associated with the cardio-metabolic risk.

The $25(\mathrm{OH}) \mathrm{D}$ is transported in the circulation, mainly bound to its specific vitamin D-binding protein, also named the GC-group component (GC). As the VDR gene [5], polymorphisms in the $G C$ gene were previously reported to be associated with plasma glucose levels [6], fasting plasma insulin levels [7] and the percentage of fat mass in Caucasian nuclear families [8].

In previous studies of $25(\mathrm{OH}) \mathrm{D}$, variants of genes involved in vitamin D transport (GC), hydroxylation/

\section{() Biomed Central}


dehydroxylation (CYP2R1 and CYP24A1), and NADSYN1 were reported to modulate vitamin D status [9-11]. The NADSYN1 gene encodes nicotinamide adenine dinucleotide synthetase 1 (NADSYN1), which is one of the glutamine-dependent enzymes involved in cholesterol synthesis and favors the production of nicotinamide adenine dinucleotide $(\mathrm{NAD}+)$, the main coenzyme required for energy production and lipid synthesis [12]. Nevertheless, studies of the association between overweight or dyslipidemia and polymorphisms in these genes are scarce. A recent study performed in an African-American cohort found associations between SNPs in the GC and CYP27B1 genes and $25(\mathrm{OH}) \mathrm{D}$ with a significant relation with the degree of African ancestry as assessed using skin color gradation [13].

In the French Caribbean island of Guadeloupe, which has 400,000 inhabitants, about $80 \%$ of the population is of African descent and these individuals are at risk of vitamin D insufficiency and obesity $[14,15]$.

Our aim was to assess the associations between vitamin D status, overweight, dyslipidemia and four SNPs of the GC, CYP27B1, and NADSYN1 genes in non-diabetic individuals with African ancestry.

\section{Methods}

\section{Population study}

The participants were recruited among individuals who had a clinical and biological examination at the referring Health Center of Guadeloupe. Data were collected during 2010 and 2011. For the assessment of vitamin D status, the physician included volunteers during sessions that were randomly planned. The determination of African ethnic background was based on self-report. Exclusion criteria included a history of kidney disease, diabetes, or inflammatory disease, pregnancy, and calcium or vitamin D replacement therapy. The study was approved by the inter-regional ethic committee (Sud-Ouest et OutreMer III, France). All patients gave their written informed consent to participate in this study.

\section{Data collection}

Participants were interviewed by a physician using a standard questionnaire that provided information on age, sex and use of antihypertensive and/or anti-hyperlipidemic treatments.

Height and weight were measured with participants standing without shoes and lightly clothed. Body mass index (BMI) was calculated as weight/height $\left(\mathrm{kg} / \mathrm{m}^{2}\right)$. Waist circumference $(\mathrm{cm})$ was measured above the iliac crests and below the lowest rib margin at minimal respiration with participants standing. The measurements were performed by trained nurses. Systolic and diastolic blood pressures were assessed using automated monitors after resting for at least $5 \mathrm{~min}$. The retained values were the average of two readings (left and right arms).

\section{Laboratory measurements}

Blood samples were obtained after an overnight fast. The biochemical analyses were performed using the same methods for the whole study sample. Glycaemia was assessed using the glucose oxidase method. Cholesterol, high-density lipoprotein/cholesterol, and triglyceride levels were measured enzymatically. Plasma concentrations of $25(\mathrm{OH}) \mathrm{D}$ were measured via a chemiluminescence assay (DiaSorin SA, Antony, France), which includes $25(\mathrm{OH}) \mathrm{D} 2$ and $25(\mathrm{OH}) \mathrm{D} 3$. In this Health Center, only single measurements were available for all the parameters.

\section{Genotyping}

Genotyping was performed in 323 Afro-Caribbean individuals for SNPs that were reported to be associated with vitamin D status in individuals of European descents (11) or in African-Americans (14): rs2282679 (intron 12) in GC, rs2298849 (intron 1) in GC, rs10877012 (5' UTR) in CYP27B1, and rs12785878 (intronic region of NM_018161.4) in NADSYN1. DNA was extracted from peripheral blood samples by standard procedures. SNPs were genotyped by KBioscience Ltd using their own novel fluorescence-based competitive allele-specific PCR (KASPar) assay. Details of the method used can be found at www.kbioscience.co.uk/.

\section{Definition of clinical factors}

Obesity was defined as a BMI $\geq 30 \mathrm{~kg} / \mathrm{m}^{2}$ and overweight was defined as a BMI $\geq 25 \mathrm{~kg} / \mathrm{m}^{2}$. Abdominal obesity was defined as a waist circumference $>102 \mathrm{~cm}$ in men or $>88 \mathrm{~cm}$ in women.

Vitamin $D$ insufficiency was defined as a $25(\mathrm{OH}) \mathrm{D}$ level $<30 \mathrm{ng} / \mathrm{mL}$ and vitamin D deficiency as a $25(\mathrm{OH}) \mathrm{D}$ level $<20 \mathrm{ng} / \mathrm{mL}$.

Dyslipidemia was defined as having one of the following measurements: high-density lipoprotein/cholesterol concentration $<40 \mathrm{mg} / \mathrm{dL}$ in men and $<50 \mathrm{mg} / \mathrm{dL}$ in women, triglyceride concentration $\geq 150 \mathrm{mg} / \mathrm{dL}$, lowdensity lipoprotein/cholesterol concentration $\geq 130 \mathrm{mg} /$ $\mathrm{L}$, or the presence of a lipid-lowering treatment combined with a history of blood lipid abnormality [16].

\section{Statistical analyses}

The chi-squared test and ANCOVA were used to test percentage and mean differences between groups. Serum $25(\mathrm{OH}) \mathrm{D}$ was $\log _{10}$ transformed to approach a normal distribution.

We examined the associations between SNPs, vitamin D deficiency, vitamin $\mathrm{D}$ insufficiency, dyslipidemia and overweight status. The logistic regression models were tested including each SNP alone with adjustment for age, sex, BMI, 25(OH)D levels, or dyslipidemia, according to the dependent variable. Adjusted odds ratios (ORs) and 95\% 
confidence intervals (95\% CIs) were estimated. The SNP effects were presented as ORs associated with the genotypes.

We used a genotype score approach to evaluate the combined effects of SNPs that were significantly associated with serum $25(\mathrm{OH}) \mathrm{D}$. The genotype score is equal to the sum of the number of risk allele $(25(\mathrm{OH}) \mathrm{D}$ lowering allele) in the SNPs. To evaluate the variation in 25 $(\mathrm{OH}) \mathrm{D}$ levels associated with the genotype score, we applied simple and multiple linear regression analysis methods using serum 25(OH)D level as the dependent variable, and genotype score as the independent variables. Adjustments were performed for age, sex and BMI. The genotype score effects were assessed by the values of regression coefficients (beta) corresponding to the non-standardized regression coefficients.

The IBM SPSS Statistics software version 21.0 was used for data analyses. All tests were two-sided and a $P$ value $<0.05$ was considered significant.

\section{Results}

\section{Characteristics of the study population}

Three hundred twenty-three non-diabetic individuals were included in the study. Among the participants, 187 (58\%) were women. The mean age was $46 \pm 12$ years.

The characteristics of the population under study are shown in Table 1. Among the participants, 29\% were obese, $61 \%$ were overweight, $42 \%$ had hypertension, $58 \%$ had dyslipidemia, $57 \%$ had vitamin D insufficiency and $8 \%$ had vitamin $\mathrm{D}$ deficiency. In the whole study population, the concentration of $25(\mathrm{OH}) \mathrm{D}$ ranged from 7 to $55 \mathrm{ng} / \mathrm{mL}$ and the mean serum 25(OH)D was $29 \pm 8 \mathrm{ng} / \mathrm{mL}$.

The prevalence of obesity and overweight status were significantly higher in women than in men $(38 \% v 17 \%$, $P<0.001$ and $68 \% \vee 52 \%, P=0.004$, respectively).
The genotype distributions in the study population were within the Hardy-Weinberg equilibrium for rs2282679 T > G (0\% GG, 13\% TG, 87\% TT; $P=0.90)$, rs2298849 T > C (15\% CC, $51 \%$ TC, $34 \%$ TT; $P=0.90)$ and rs12785878 G>T (5\% TT, 33\% GT, 62\% GG; $P=$ 0.90), but not for rs10877012 G > T (25\% GT, 75\% GG; $P<$ 0.05). Consequently, the results for rs10877012 (CYP27B1) are not shown in this report.

\section{Distributions of 25(OH)D levels and metabolic parameters according to genotypes}

The distributions of $25(\mathrm{OH}) \mathrm{D}$ levels and metabolic parameters according to genotypes of GC and NADSYN1 genes are presented in Table 2.

For the rs2282679 SNP in the GC gene, lower values of serum vitamin $\mathrm{D}$, higher frequencies of vitamin $\mathrm{D}$ insufficiency and of vitamin D deficiency were observed in carriers of the TG genotype than in the remaining individuals ( $P$ values from 0.03 to 0.01 ). The association of this SNP with dyslipidemia was nearly significant $(P=0.05)$.

Significant differences were noted in frequency of vitamin D deficiency according the rs2298849 genotypes with a higher frequency in carriers of the TT genotype than in the non-carriers $(P=0.007)$. For rs12785878, higher values for mean circulating $25(\mathrm{OH})$ $\mathrm{D}(P=0.03)$ and lower frequency of vitamin $\mathrm{D}$ insufficiency $(P=0.01)$ and dyslipidemia $(P=0.04)$ were noted in carriers of the minor allele (TT/GT) compared with the remainder of the cohort.

Regarding the associations of the three SNPs studied with overweight or obesity according to sex, a higher frequency of overweight was noted in women carrying rs2298849T allele vs CC carriers $(71 \% v 50 \%$; $P=0.035)$ (Table 3). In men, no relationship was found between obesity or overweight and the three SNPs studied.

Table 1 Characteristics of the study population

\begin{tabular}{|c|c|c|c|c|c|c|c|}
\hline Variables & $\mathbf{N}$ & All subjects & Men & & Women & & $P$ \\
\hline $\operatorname{Sex}(F)(n(\%))$ & 323 & $136(58)$ & 136 & - & 187 & - & \\
\hline Age (years) & 323 & $46 \pm 12$ & 136 & $41 \pm 12$ & 187 & $47 \pm 12$ & 0.42 \\
\hline Waist circumference $(\mathrm{cm})$ & 307 & $89 \pm 13$ & 130 & $89 \pm 11$ & 177 & $90 \pm 14$ & 0.40 \\
\hline Body mass index $\left(\mathrm{Kg} / \mathrm{m}^{2}\right)$ & 323 & $27 \pm 6$ & 136 & $25 \pm 4$ & 187 & $29 \pm 7$ & $<0.001$ \\
\hline Glycaemia (mmol/L) & 323 & $4.6 \pm 1.2$ & 136 & $4.9 \pm 1.6$ & 187 & $4.5 \pm 0.9$ & 0.003 \\
\hline $25(\mathrm{OH}) \mathrm{D}(\mathrm{ng} / \mathrm{mL})$ & 323 & $29 \pm 8$ & 136 & $30 \pm 8$ & 187 & $28 \pm 7$ & 0.006 \\
\hline Overweight (n (\%)) & 323 & $198(61)$ & 136 & $71(52)$ & 187 & $127(68)$ & 0.004 \\
\hline Obesity (n (\%)) & 323 & $94(29)$ & 136 & $23(17)$ & 187 & $71(38)$ & $<0.001$ \\
\hline Abdominal obesity (n (\%)) & 307 & $108(35)$ & 130 & $13(10)$ & 177 & $95(54)$ & $<0.001$ \\
\hline Hypertension (n (\%)) & 323 & $136(42)$ & 136 & $56(41)$ & 187 & $80(43)$ & 0.77 \\
\hline Dyslipidemia (n (\%)) & 319 & $184(58)$ & 135 & $69(51)$ & 184 & $115(63)$ & 0.04 \\
\hline Vitamin D Insufficiency (n (\%)) & 323 & $183(57)$ & 136 & $68(50)$ & 187 & $115(62)$ & 0.04 \\
\hline
\end{tabular}

The data are presented as mean \pm SD or number (\%). 
Table 2 Distribution of 25(OH)D levels and metabolic parameters according to genotypes of GC and NADSYN1 genes

\begin{tabular}{|c|c|c|c|c|c|c|}
\hline \multirow[b]{2}{*}{ rs2282679 T > G (GC) } & \multicolumn{3}{|c|}{ Genotypes } & \multirow[b]{2}{*}{$P^{*}$} & \multirow[t]{2}{*}{ Dominant model } & \multirow[t]{2}{*}{ Recessive mode } \\
\hline & GG & TG & $\mathrm{TT}$ & & & \\
\hline$(N=323)$ & 0 & 43 & 280 & & & \\
\hline $25(\mathrm{OH}) \mathrm{D}(\mathrm{ng} / \mathrm{mL})$ & - & $26.4 \pm 8.3$ & $29.0 \pm 7.4$ & 0.03 & - & - \\
\hline Vitamin D Insufficiency & - & $72 \%$ & $54 \%$ & 0.03 & - & - \\
\hline Vitamin D Deficiency & - & $19 \%$ & $6 \%$ & 0.01 & - & - \\
\hline Overweight & - & $67 \%$ & $60 \%$ & 0.37 & - & - \\
\hline Obesity & - & $35 \%$ & $28 \%$ & 0.37 & - & - \\
\hline Abdominal obesity & - & $42 \%$ & $34 \%$ & 0.36 & - & - \\
\hline Dyslipidemia & - & $44 \%$ & $60 \%$ & 0.05 & - & - \\
\hline rs2298849 T > C (GC) & $\mathrm{CC}$ & TC & $\mathrm{TT}$ & $P^{*}$ & $P$ & $P$ \\
\hline$(N=323)$ & 49 & 165 & 109 & & & \\
\hline $25(\mathrm{OH}) \mathrm{D}(\mathrm{ng} / \mathrm{mL})$ & $28.3 \pm 6.9$ & $28.5 \pm 7.7$ & $29.0 \pm 7.8$ & 0.87 & 0.60 & 0.76 \\
\hline Vitamin D Insufficiency & $53 \%$ & $60 \%$ & $53 \%$ & 0.46 & 0.37 & 0.58 \\
\hline Vitamin D Deficiency & $6 \%$ & $5 \%$ & $14 \%$ & 0.03 & 0.007 & 0.50 \\
\hline Overweight & $51 \%$ & $61 \%$ & $66 \%$ & 0.20 & 0.21 & 0.11 \\
\hline Obesity & $22 \%$ & $32 \%$ & $28 \%$ & 0.46 & 0.85 & 0.26 \\
\hline Abdominal obesity & $28 \%$ & $39 \%$ & $33 \%$ & 0.32 & 0.37 & 0.27 \\
\hline Dyslipidemia & $53 \%$ & $63 \%$ & $51 \%$ & 0.13 & 0.11 & 0.48 \\
\hline rs12785878 G > T & $\mathrm{TT}$ & GT & GG & $P^{*}$ & $P$ & $P$ \\
\hline$(N A D S Y N 1)(N=318)$ & 15 & 106 & 197 & & & \\
\hline $25(\mathrm{OH}) \mathrm{D}(\mathrm{ng} / \mathrm{mL})$ & $27.7 \pm 7.1$ & $30.2 \pm 8.3$ & $27.8 \pm 7.1$ & 0.05 & 0.03 & 0.69 \\
\hline Vitamin D Insufficiency & $53 \%$ & $47 \%$ & $62 \%$ & 0.04 & 0.01 & 0.77 \\
\hline Vitamin D Deficiency & $13 \%$ & $5 \%$ & $10 \%$ & 0.25 & 0.23 & 0.46 \\
\hline Overweight & $40 \%$ & $62 \%$ & $62 \%$ & 0.22 & 0.60 & 0.08 \\
\hline Obesity & $20 \%$ & $33 \%$ & $28 \%$ & 0.50 & 0.85 & 0.40 \\
\hline Abdominal obesity & $21 \%$ & $39 \%$ & $34 \%$ & 0.37 & 0.37 & 0.17 \\
\hline Dyslipidemia & $60 \%$ & $49 \%$ & $62 \%$ & 0.08 & 0.04 & 0.83 \\
\hline
\end{tabular}

The data are presented as mean (SD) or column percentage. Significant $\mathrm{P}$ values are presented in bold.

*P values for comparisons between genotypes.

Logistic regression of vitamin D deficiency, vitamin D insufficiency, dyslipidemia and overweight.

Table 4 presents the adjusted odds ratios (OR) for risk of vitamin $\mathrm{D}$ deficiency, vitamin $\mathrm{D}$ insufficiency, dyslipidemia and overweight according to the GC and the NADSYN1 genotypes. For rs2282679, carrying the $\mathrm{G}$ allele increased the risk of vitamin $\mathrm{D}$ deficiency and of vitamin $\mathrm{D}$ insufficiency

Table 3 Frequencies of overweight according to rs2298849 $\mathrm{T}>\mathrm{C}$ genotypes in men and women

\begin{tabular}{|c|c|c|c|c|c|c|}
\hline & MEN & & & WOMEN & & \\
\hline & $N=136$ & & & $N=187$ & & \\
\hline Overweight & TT-TC & CC & $P$ & TT-TC & $\mathrm{CC}$ & $P$ \\
\hline & $n=103$ & $n=23$ & & $n=161$ & $n=26$ & \\
\hline No & $44(48)$ & $11(48)$ & 0.99 & $47(29)$ & $13(50)$ & 0.035 \\
\hline Yes & $59(52)$ & $12(52)$ & & $114(71)$ & $13(50)$ & \\
\hline
\end{tabular}

The data are presented number (column percentage). (adjusted $\mathrm{OR}=3.53, P=0.008$ and adjusted $\mathrm{OR}=2.34, P=$ 0.02 respectively) in comparison with the TT genotype and surprisingly with a decreased risk of dyslipidemia.The odds of vitamin D deficiency was significantly increased for rs2298849 TT carriers in comparison with the rs2298849C allele carriers (adjusted $3.40=1.46, P=0.004$ ) and that of vitamin $D$ insufficiency was significantly increased for rs12785878 GG carriers (adjusted OR $=1.80, P=0.01$ ) in comparison to $\mathrm{T}$ allele carriers. The rs12785878 was also associated with an increased risk of dyslipidemia.

\section{Serum 25(OH)D levels in relation to genotype score}

The risk alleles $(25(\mathrm{OH}) \mathrm{D}$ lowering allele) were $\mathrm{G}$ for rs2282679, T for rs2298849 and G for rs12785878. The high risk alleles of rs2282679 and rs12785878 were combined and the range of the genotype score was $0-3$. The genotype score was significantly related to $25(\mathrm{OH}) \mathrm{D}$ and mean serum 25(OH)D levels $(95 \% \mathrm{CI})$ were 30.1 (28.6 - 
Table 4 Logistic regressions of vitamin D deficiency, vitamin D insufficiency, dyslipidemia and overweight for polymorphisms in GC and NADSYN1

\begin{tabular}{|c|c|c|c|c|c|c|c|c|}
\hline & \multirow{2}{*}{\multicolumn{2}{|c|}{$\frac{\text { Vitamin D }}{\text { deficiency }}$}} & \multirow{2}{*}{\multicolumn{2}{|c|}{$\frac{\text { Vitamin D }}{\text { Insufficiency }}$}} & \multirow{2}{*}{\multicolumn{2}{|c|}{ Dyslipidemia }} & \multirow{2}{*}{\multicolumn{2}{|c|}{ Overweight }} \\
\hline & & & & & & & & \\
\hline & Adjusted & $P$ & Adjusted & $P$ & Adjusted & $P$ & Adjusted & $P$ \\
\hline & OR $(95 \% \mathrm{Cl})$ & & OR $(95 \% \mathrm{Cl})$ & & OR $(95 \% \mathrm{Cl})$ & & OR $(95 \% \mathrm{Cl})$ & \\
\hline \multicolumn{9}{|c|}{$G C$ rs2282679 T>G } \\
\hline$\Pi$ & 1 & & 1 & & 1 & & 1 & \\
\hline TG- GG & $3.53(1.38-9.80)$ & 0.008 & $2.34(1.15-4.90)$ & 0.02 & $0.41(0.21-0.84)$ & 0.01 & $1.60(0.70-3.36)$ & 0.20 \\
\hline \multicolumn{9}{|c|}{$G C$ rs2298849 $T>C$} \\
\hline CC - TC & 1 & & 1 & & 1 & & 1 & \\
\hline Tा & $3.40(1.46-7.89)$ & 0.004 & $0.82(0.51-1.31)$ & 0.41 & $0.67(0.40-1.11)$ & 0.12 & $1.76(1.04-2.98)$ & 0.04 \\
\hline \multicolumn{9}{|c|}{ NADSYN1 rs12785878 G>T } \\
\hline$\Pi \mathrm{T}$ - GT & 1 & & 1 & & 1 & & 1 & \\
\hline GG & $1.72(0.69-4.24)$ & 0.54 & $1.80(1.12-2.87)$ & 0.01 & $1.72(1.04-2.86)$ & 0.03 & $1.02(0.62-1.69)$ & 0.93 \\
\hline
\end{tabular}

Vitamin D deficiency and vitamin D insufficiency: adjustment for age, sex, BMI, dyslipidemia. Dyslipidemia: adjustment for age, sex, BMI, 25(OH)D levels. Overweight: adjustment for age, sex, 25(OH)D levels, dyslipidemia. The adjusted odds ratios are provided, separately for each SNP. Significant P values are presented in bold.

31..6) $\mathrm{ng} / \mathrm{mL}$ for score $0-1,28.3(27.2$ - 29.3) $\mathrm{ng} / \mathrm{mL}$ for score 2 and $24.7(22.0-27.3) \mathrm{ng} / \mathrm{mL}$ for score $3, P=$ 0.007 (Figure 1).

Table 5 presents the results of the linear regressions between the genotype scores across the rs2282679 and rs12785878 SNPs and serum 25(OH)D levels. Genotype score of $0-1$ was considered as referent. In model 1 (1a, $1 \mathrm{~b}, 1 \mathrm{c})$ with the simple linear regression and considering each SNP alone, significant average change in $25(\mathrm{OH}) \mathrm{D}$ levels were noted for a rs2282679 genotype score of 2 (vs 1) (model 1a) and for a rs12785878 genotype score of 2 (vs $0-1$ ) (model 1c). These both models accounted for $1 \%\left(R^{2}=0.01\right)$ and $2 \%\left(R^{2}=0.02\right)$, of the variation in $25(\mathrm{OH}) \mathrm{D}$ levels, respectively. In the multiple linear regression, the average change in $25(\mathrm{OH}) \mathrm{D}$ levels remained significant with multiple $\mathrm{R}^{2}$ of 0.06 for both

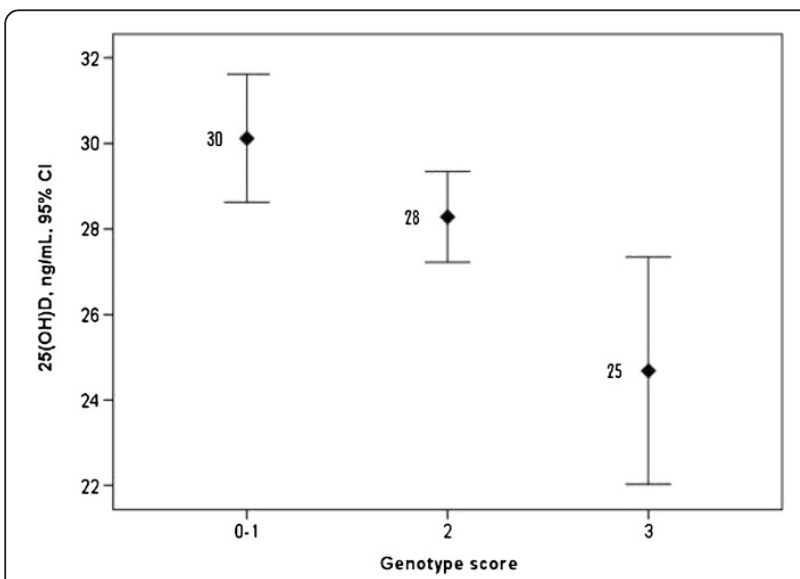

Figure 1 Mean serum 25(OH)D levels and 95\% confidence intervals according to genotype scores of two SNPs (rs2282679 $\mathrm{T}>\mathrm{G}$ and rs2298849 T $>\mathrm{C}$ ). $P=0.007$. models. The rs2298849 genotype score was not significantly associated with $25(\mathrm{OH}) \mathrm{D}$ levels. We also noted that BMI was not related to the genotype score of the three SNPs (rs2282679; $P=0.75$, rs2298849; $P=0.65$, rs12785878; $P=0.75$, data not shown).

In models 2, and in the simple regression, progressive reductions in $25(\mathrm{OH}) \mathrm{D}$ levels were noted for score 2 and 3 (compared to $0-1)$ : beta $=-1.8 \mathrm{ng} / \mathrm{mL} \quad(P=0.04)$ and beta $=-5.4 \mathrm{ng} / \mathrm{mL}(P=0.02)$ respectively. In the multiple regression with adjustment for age, sex and BMI, the statistically significant average change in 25 $(\mathrm{OH}) \mathrm{D}$ levels for score of 3 (vs $0-1$ ) was $-5.5 \mathrm{ng} / \mathrm{mL}$ $(P=0.001)$ with $\mathrm{R}^{2}$ of 0.08 . The combination of both genotype scores accounted for a $2 \%$ increase of $\mathrm{R}^{2}$. Conversely, this genotype score was not associated with BMI (data not shown).

\section{Discussion}

In this study examining the relationship between vitamin D status and SNPs of the vitamin D-binding protein (GC) and NADSYN1 genes in non-diabetic individuals with African ethnic background, we found significant associations between rs2282679 (GC), rs2298849 (GC), and rs12785878 (NADSYN1) and vitamin D status. Significant associations were also noted with overweight for rs2298849 and with dyslipidemia for rs12785878 and rs2282679.

In this study population living in a sunny climate, the prevalence of vitamin D insufficiency was $57 \%$ and that of vitamin D deficiency was $8 \%$. These prevalence values were globally lower than that observed in AfricanAmerican individuals living in countries with a temperate climate $[14,17]$. The effect of sunshine on vitamin D levels is widely recognized. 
Table 5 Linear regression: between serum 25-hydroxyvitamin D levels and genotype scores for rs2282679, rs2298849, rs12785878

\begin{tabular}{|c|c|c|c|c|c|c|c|}
\hline & \multirow[b]{2}{*}{ Genotype score } & \multicolumn{3}{|c|}{ Simple linear regression } & \multicolumn{3}{|c|}{ Multiple linear regression** } \\
\hline & & Beta* & $P$ & $\mathrm{R}^{2}$ for the model & Beta* & $P$ & $R^{2}$ for the model \\
\hline Model $1 a$ risk allele $\mathbf{G}$ for $\mathbf{r s 2 2 8 2 6 7 9 ~} \mathrm{T}>\mathrm{G}$ & 2 (vs 1) & -2.5 & 0.04 & 0.01 & -2.6 & 0.03 & 0.06 \\
\hline Model $\mathbf{1 b}$ risk allele $\mathbf{T}$ for $\mathbf{r s 2 2 9 8 8 4 9} T>C$ & 2 (vs $0-1$ ) & 0.70 & 0.43 & 0.002 & & & \\
\hline Model 1 c risk allele $\mathbf{G}$ for $\mathbf{r s} 12785878 \mathrm{G}>\mathrm{T}$ & 2 (vs $0-1)$ & -1.5 & 0.04 & 0.01 & -2.1 & 0.02 & 0.06 \\
\hline \multicolumn{8}{|l|}{ Model 2} \\
\hline \multicolumn{8}{|l|}{ risk alleles $\mathbf{G}$} \\
\hline \multirow[t]{2}{*}{ for $\mathbf{r s 2 2 8 2 6 7 9} T>G$ and $\mathbf{r s 1 2 7 8 5 8 7 8} G>T$} & 2 (vs $0-1$ ) & -1.8 & 0.04 & 0.03 & -1.6 & 0.06 & 0.08 \\
\hline & 3 (vs $0-1)$ & -5.4 & 0.02 & & -5.5 & 0.001 & \\
\hline
\end{tabular}

Model 1a, $1 b$ include genotype scores for each SNP alone. Model 2 includes genotype scores for rs2282679 and rs 12785878 combined.

Genotype score equals the sum of the number of risk alleles.*Beta: average change in serum $25(\mathrm{OH}) \mathrm{D}$ level (ng/mL) associated with the genotype. Regression: ** with adjustment for age, sex, BMI.

The vitamin D-binding protein, which is also known as the group-specific component (GC), is the main transporter of vitamin D [10]. The concentration of this serum glycoprotein influences $25(\mathrm{OH}) \mathrm{D}$ levels and modulates the rates of its bioavailability [18-20]. The GC gene is localized on chromosome 4 (4q12-q13), encodes a single-chain polypeptide that comprises 474 amino acid residues and belongs to the albumin family $[10,21-23]$.

Our results regarding vitamin D corroborate previous reports which showed associations between vitamin D levels and rs2282679 and rs2298849 in the GC gene in African-Americans [13], rs2282679 in Caucasians in two genome wide association (GWA) studies [9,11] and rs2298849 in 496 healthy individuals [12]. In addition, the genotype distributions of the two GC SNPs in our African-Caribbean population were close to those observed in the study conducted among AfricanAmericans individuals [13] for rs2282679 $(0.2 \%$ for the rare homozygote, $15.2 \%$ for the heterozygote and the, $84.5 \%$ for the frequent homozygote genotype) and for rs2298849 (16.4\% for the rare homozygote, $46.2 \%$ for the heterozygote and $37.4 \%$ for the frequent homozygote genotype).

The effects of CYP27B1 and NADSYN1 on circulating $25(\mathrm{OH}) \mathrm{D}$ were also reported in these studies $[9,11]$ and confirmed in a recent study in Han Chinese children [24]. Two other SNPs in the GC gene, rs4588 and rs7041, which have been more commonly studied, exhibited significant associations with the levels of $25(\mathrm{OH}) \mathrm{D}$ and 1,25 $(\mathrm{OH}) 2 \mathrm{D}$ in Hispanic- and African-Americans [25], in Caucasian women [26], and in young Canadian adults of East-Asian, European, and South-Asian ancestry [19].

The relationship between the NADSYN1 gene and vitamin $\mathrm{D}$ status has been less studied. The NADSYN1 gene is located on chromosome 11 (11q13.4), close to the dehydrocholesterol reductase (DHCR7) gene, which encodes 7-dehydrocholesterol reductase, an enzyme involved in the conversion of 7-dehydrocholesterol into cholesterol in human skin [27]. A recent GWA study revealed that variants near genes involved in cholesterol synthesis influence the vitamin D status [11]. The rs12785878 GG genotype was associated with an increased risk of vitamin D insufficiency and of dyslipidemia in our study. This association with dyslipidemia has not already been reported but, mutations in DHCR7 are associated with Smith-Lemli-Opitz Syndrome in which homozygous individuals present low serum cholesterol levels $[11,28]$ associated with other abnormalities.

Although vitamin D deficiency has been consistently associated with obesity, some authors failed to observe an association between BMI and some genetic variants in the vitamin $\mathrm{D}$ pathway while they were associated with 25(OH)D levels [29-32]. According to some others, this lack of association could be explained by the fact that linear increases in serum $25(\mathrm{OH}) \mathrm{D}$ would not have a substantial influence on BMI [32]. Interestingly, our results highlighted a significant association between the rs2298849 alone and overweight (i.e. taking into account the BMI as a categorical variable) while no relationship was found between the rs2298849 genotype score and BMI. We also noted a sex difference in this relationship with women carrying the TT/TC genotypes exhibiting a higher frequency of overweight compared with those carrying the $\mathrm{CC}$ genotype, whereas no relationship was found in men. In a study in Caucasian nuclear families, the authors also found a female-specific association between another SNP (rs17467825) in GC and the percentage of fat mass [8]. This sex-specific association suggests disparities in the sensitivity to the SNP related to female (such as estrogen) or male (such as testosterone) hormones. A possible effect of sex-hormone-binding globulin should be considered. This hormone binds and transports the sex steroid hormones (mainly testosterone) in the circulation [33] and its variation may contribute to susceptibility to metabolic and cardiovascular outcomes [34]. Additionally, in a recent study in Chinese 
women, while the authors did not find an association between BMI and SNPs in the GC gene, BMI was associated with two other SNPs of the vitamin D pathway genes (rs22488359 in CYP24A1 and rs10832313 in CYP2R1) [35]. This is not surprising, given that ethnic disparities in the relationships between genes and diseases have been widely reported.

The results of the linear regression of $25(\mathrm{OH}) \mathrm{D}$ showed that the genotype score based on rs2282679 in GC and rs12785878 in NADSYN1 alone accounted for $3 \%$ of the variation in $25(\mathrm{OH}) \mathrm{D}$. The addition of age, sex and $\mathrm{BMI}$ in the multivariate model increased the $\mathrm{R}^{2}$ by $5 \%$. The variation in $25(\mathrm{OH}) \mathrm{D}$ associated with the genetic factors is not very high [13]. Other factors such as sun exposure, diet, ethnicity and season contributed more significantly to this variation [36] and may also interact with genetic effects on vitamin D status. Nevertheless, our results showing a significant average change in $25(\mathrm{OH}) \mathrm{D}$ levels of $-5.5 \mathrm{ng} / \mathrm{mL}$ for a score of 3 (vs 0 1 ), is an important finding in our Afro-Caribbean population at risk of vitamin $\mathrm{D}$ insufficiency.

It should be noted that the present study had some limitations, including a small sample size although the overall population of the island is also small (400 000 inhabitants). Because of their low power, studies on small samples can lead to false positive or false negative results. In addition, the concentrations of serum $25(\mathrm{OH}) \mathrm{D}$ were examined using a single measurement for each subject. However, our study also had considerable strengths. First, all participants had high skin pigmentation and were living on an island which has annually a sunny climate. This is of importance since ethnic variation in the $G C$ gene has been described [10] and seasonal variations are involved in the metabolism of vitamin D. Second, the exclusion of patients with diabetes from the study minimized the impact of insulin resistance/dependence [37] on the association between SNPs, serum 25(OH)D levels, and other risk factors. Our findings corroborated those previously reported in European and African-American individuals regarding genetic associations with vitamin D status and extended the relevant studies for a specific population sample. Third, this study is the first to analyze the effects of SNPs in the $G C$ and NADSYN1 genes concomitantly on three cardio-metabolic risk factors (overweight, dyslipidemia, and vitamin D insufficiency/deficiency).

\section{Conclusions}

Although the role of genetic factors in the metabolism of vitamin D is recognized, much remains to be understood regarding this relationship. Our results obtained from non-diabetic Afro-Caribbean individuals confirm the associations of the GC and NADSYN1 genes with vitamin D status and suggest that polymorphisms in these genes contribute to dyslipidemia and overweight independently of 25 hydroxyvitamin D levels. As vitamin $\mathrm{D}$ status is linked to several adverse outcomes [38], genetic variants associated with vitamin D levels may also play a role in the etiology of these diseases. Thus, it will be of interest to confirm these findings in other populations and ethnic groups.

\section{Abbreviations}

25(OH)D: 25 hydroxyvitamin D; BMI: Body mass index; GC: Group specific component; CYP2R1: Cytochrome P450, family 2, subfamily R, polypeptide 1 ; NADSYN1: Nicotinamide adenine dinucleotidesynthetase 1; SNPs: Single nucleotide polymorphisms; VitD: Vitamin D; GWAS: Genome-wide association study.

\section{Competing interests}

The authors declare that they have no competing interests.

\section{Authors' contributions}

LF conceived of the study and participated in its design, performed the statistical analysis and involved in writing of the manuscript. FLVC, participated in the design of the study and involved in writing of the manuscript. LL, JD, CA, CF, MLP, LLi, FB involved in writing of the manuscript. $J$ P, JDu participated in the design and coordination of the study. All authors read and approved the final manuscript.

\section{Acknowledgements}

This work was supported by grants from the University Hospital of Guadeloupe, France. We thank all the physicians and the nurses of the Health Centre of Guadeloupe and all individuals who participated in this study. We also thank Dr Catherine Massart for her contribution.

\section{Author details}

${ }^{1}$ Research group Clinical Epidemiology and MedicineResearch group, University of Antilles and Guyane, Guyane, France. ${ }^{2}$ Department of Public Health and Medical Information, University Hospital of Pointe-à-Pitre, Guadeloupe, France. ${ }^{3}$ Diabetology Unit, University Hospital of Pointe-à-Pitre, Guadeloupe, France. ${ }^{4}$ Health Centre, AGREXAM, Les Abymes, Guadeloupe, France. ${ }^{5}$ Clinical Genetic Unit, University Hospital of Pointe-à-Pitre, Guadeloupe, France. ${ }^{6}$ Department of Epidemiology and Biostatistics, Drexel University School of Public Health, Philadelphia, PA, USA.

${ }^{7}$ Endocrinology-Diabetology and nutrition Unit, University Hospital South of Rennes, Rennes, France. ${ }^{8}$ Nephrology Unit, University Hospital of Pointeà-Pitre, Guadeloupe, France. ${ }^{9}$ Département de Santé Publique, CHU de Pointe-à-Pitre, 97159 Pointe-à-Pitre, Guadeloupe, France.

Received: 6 June 2013 Accepted: 26 September 2013

Published: 29 September 2013

\section{References}

1. Rodriguez-Rodriguez E, Navia B, Lopez-Sobaler AM, Ortega RM: Vitamin D in overweight/obese women and its relationship with dietetic and anthropometric variables. Obesity (Silver Spring) 2009, 17(4):778-782.

2. Chacko SA, Song Y, Manson JE, Van Horn L, Eaton C, Martin LW, McTiernan A, Curb JD, Wylie-Rosett J, Phillips LS, et al: Serum 25-hydroxyvitamin D concentrations in relation to cardiometabolic risk factors and metabolic syndrome in postmenopausal women. Am J Clin Nutr 2011, 94(1):209-217.

3. Chowdhury TA, Boucher BJ, Hitman GA: Vitamin D and type 2 diabetes: Is there a link?Prim Care. Diabetes 2009, 3(2):115-116.

4. Wang TJ, Pencina MJ, Booth SL, Jacques PF, Ingelsson E, Lanier K, Benjamin EJ, D'Agostino RB, Wolf M, Vasan RS: Vitamin D deficiency and risk of cardiovascular disease. Circulation 2008, 117(4):503-511.

5. Ferrarezi DA, Bellili-Munoz N, Nicolau C, Cheurfa N, Guazzelli IC, Frazzatto E, Velho $G$, Villares SM: Allelic variations in the vitamin D receptor gene, insulin secretion and parents' heights are independently associated with height in obese children and adolescents. Metabolism 2012, 61(10):1413-1421.

6. Pratley RE, Thompson DB, Prochazka M, Baier L, Mott D, Ravussin E, Sakul H, Ehm MG, Burns DK, Foroud T, et al: An autosomal genomic scan for loci 
linked to prediabetic phenotypes in Pima Indians. J Clin Invest 1998, 101(8):1757-1764.

7. Hirai M, Suzuki S, Hinokio Y, Hirai A, Chiba M, Akai H, Suzuki C, Toyota T: Variations in vitamin D-binding protein (group-specific component protein) are associated with fasting plasma insulin levels in Japanese with normal glucose tolerance. J Clin Endocrinol Metab 2000, 85(5):1951-1953.

8. Jiang $H$, Xiong DH, Guo YF, Shen H, Xiao P, Yang F, Chen Y, Zhang F, Recker RR, Deng HW: Association analysis of vitamin D-binding protein gene polymorphisms with variations of obesity-related traits in Caucasian nuclear families. Int J Obes (Lond) 2007, 31(8):1319-1324.

9. Ahn J, Yu K, Stolzenberg-Solomon R, Simon KC, McCullough ML, Gallicchio $L$, Jacobs EJ, Ascherio A, Helzlsouer K, Jacobs KB, et al: Genome-wide association study of circulating vitamin D levels. Hum Mol Genet 2010, 19(13):2739-2745.

10. Speeckaert M, Huang G, Delanghe JR, Taes YE: Biological and clinical aspects of the vitamin D binding protein (Gc-globulin) and its polymorphism. Clin Chim Acta 2006, 372(1-2):33-42.

11. Wang TJ, Zhang F, Richards JB, Kestenbaum B, van Meurs JB, Berry D, Kiel DP, Streeten EA, Ohlsson C, Koller DL, et al: Common genetic determinants of vitamin D insufficiency: a genome-wide association study. Lancet 2010, 376(9736):180-188.

12. Bu FX, Armas L, Lappe J, Zhou Y, Gao G, Wang HW, Recker R, Zhao L: Comprehensive association analysis of nine candidate genes with serum 25-hydroxy vitamin D levels among healthy Caucasian subjects. Hum Genet 2010, 128(5):549-556.

13. Signorello LB, Shi J, Cai Q, Zheng W, Williams SM, Long J, Cohen SS, Li G, Hollis BW, Smith JR, et al: Common variation in vitamin D pathway genes predicts circulating 25-hydroxyvitamin D Levels among African Americans. PLoS One 2011, 6(12):e28623.

14. Foucan L, Ducros J, Merault H: Vitamin D status in dark-skinned patients undergoing hemodialysis in a continually sunny country. J Nephrol 2012 25(6):983-988

15. Velayoudom-Cephise FL, Larifla L, Donnet JP, Maimaitiming S, Deloumeaux J, Blanchet A, Massart C, Munoz-Bellili N, Merle S, Chout R, et al: Vitamin D deficiency, vitamin $D$ receptor gene polymorphisms and cardiovascular risk factors in Caribbean patients with type 2 diabetes. Diabetes Metab 2011, 37(6):540-545.

16. Third Report of the National Cholesterol Education Program (NCEP) Expert Panel on Detection: Evaluation, and Treatment of High Blood Cholesterol in Adults (Adult Treatment Panel III) final report. Circulation 2002, 106(25):3143-3421.

17. Ginde AA, Liu MC, Camargo CA Jr: Demographic differences and trends of vitamin D insufficiency in the US population, 1988-2004. Arch Intern Med 2009, 169(6):626-632

18. Chun RF: New perspectives on the vitamin D binding protein. Cell Biochem Funct 2012, 30(6):445-456.

19. Gozdzik A, Zhu J, Wong BY, Fu L, Cole DE, Parra EJ: Association of vitamin $D$ binding protein (VDBP) polymorphisms and serum 25(OH)D concentrations in a sample of young Canadian adults of different ancestry. J Steroid Biochem Mol Biol 2011, 127(3-5):405-412.

20. Safadi FF, Thornton P, Magiera H, Hollis BW, Gentile M, Haddad JG, Liebhaber SA, Cooke NE: Osteopathy and resistance to vitamin D toxicity in mice null for vitamin D binding protein. J Clin Invest 1999, 103(2):239-251.

21. Belsey R, Clark MB, Bernat M, Glowacki J, Holick MF, DeLuca HF, Potts JT Jr: The physiologic significance of plasma transport of vitamin $D$ and metabolites. Am J Med 1974, 57(1):50-56.

22. Christiansen M, Jorgensen CS, Laursen I, Hirschberg D, Hojrup P, Houen G: Protein chemical characterization of Gc globulin (vitamin D-binding protein) isoforms; Gc-1f, Gc-1s and Gc-2. Biochim Biophys Acta 2007, 1774(4):481-492.

23. Daiger SP, Schanfield MS, Cavalli-Sforza LL: Group-specific component (Gc) proteins bind vitamin D and 25-hydroxyvitamin D. Proc Natl Acad Sci U S A 1975, 72(6):2076-2080.

24. Zhang Y, Wang X, Liu Y, Qu H, Qu S, Wang W, Ren L: The GC, CYP2R1 and DHCR7 genes are associated with vitamin D levels in northeastern Han Chinese children. Swiss Med Wkly 2012, 142:w13636.

25. Engelman CD, Fingerlin TE, Langefeld CD, Hicks PJ, Rich SS, Wagenknecht $L E$, Bowden DW, Norris JM: Genetic and environmental determinants of 25-hydroxyvitamin D and 1,25-dihydroxyvitamin D levels in Hispanic and African Americans. J Clin Endocrinol Metab 2008, 93(9):3381-3388.
26. Sinotte M, Diorio C, Berube S, Pollak M, Brisson J: combined binding protein and plasma concentrations of 25-hydroxyvitamin $D$ in premenopausal women. Am J Clin Nutr 2009, 89(2):634-640.

27. Waterham HR, Wanders RJ: Biochemical and genetic aspects of 7dehydrocholesterol reductase and Smith-Lemli-Opitz syndrome. Biochim Biophys Acta 2000, 1529(1-3):340-356.

28. Tint GS, Irons M, Elias ER, Batta AK, Frieden R, Chen TS, Salen G: Defective cholesterol biosynthesis associated with the Smith-Lemli-Opitz syndrome. N Engl J Med 1994, 330(2):107-113.

29. Dorjgochoo T, Shi J, Gao YT, Long J, Delahanty R, Xiang YB, Cai Q, Shu XO: Genetic variants in vitamin $D$ metabolism-related genes and body mass index: analysis of genome-wide scan data of approximately 7000 Chinese women. Int J Obes (Lond) 2012, 36(9):1252-1255.

30. Speliotes EK, Willer CJ, Berndt SI, Monda KL, Thorleifsson G, Jackson AU, Lango Allen H, Lindgren CM, Luan J, Magi R, et al: Association analyses of 249,796 individuals reveal 18 new loci associated with body mass index. Nat Genet 2010, 42(11):937-948.

31. Jorde R, Schirmer H, Wilsgaard T, Joakimsen RM, Mathiesen EB, Njolstad I, Lochen ML, Figenschau Y, Berg JP, Svartberg J, et al: Polymorphisms related to the serum 25 -hydroxyvitamin $D$ level and risk of myocardial infarction, diabetes, cancer and mortality. The Tromso Study. PLoS One 2012, 7(5):e37295

32. Vimaleswaran KS, Berry DJ, Lu C, Tikkanen E, Pilz S, Hiraki LT, Cooper JD, Dastani Z, Li R, Houston DK, et al: Causal relationship between obesity and vitamin D status: bi-directional Mendelian randomization analysis of multiple cohorts. PLoS Med 2013, 10(2):e1001383.

33. Coviello AD, Haring R, Wellons M, Vaidya D, Lehtimaki T, Keildson S, Lunetta $\mathrm{KL}$, He C, Fornage M, Lagou V, et al: A genome-wide association metaanalysis of circulating sex hormone-binding globulin reveals multiple Loci implicated in sex steroid hormone regulation. PLOS Genet 2012, 8(7):e1002805

34. Wildman RP, Wang D, Fernandez I, Mancuso P, Santoro N, Scherer PE, Sowers MR: Associations of Testosterone and Sex Hormone Binding Globulin with Adipose Tissue Hormones in Midlife Women. Obesity (Silver Spring) 2013, 21(3):629-636.

35. Dorjgochoo T, Shi J, Gao YT, Long J, Delahanty R, Xiang YB, Cai Q, Shu XO: Genetic variants in vitamin $D$ metabolism-related genes and body mass index: analysis of genome-wide scan data of approximately 7000 Chinese women. Int J Obes (Lond) 2011, 36(9):1252-1255.

36. Skaaby T, Husemoen LL, Martinussen T, Thyssen JP, Melgaard M, Thuesen BH, Pisinger $C$, Jorgensen $T$, Johansen JD, Menne T, et al: Vitamin D status, filaggrin genotype, and cardiovascular risk factors: a Mendelian randomization approach. PLoS One 2013, 8(2):e57647.

37. Hurskainen AR, Virtanen JK, Tuomainen TP, Nurmi T, Voutilainen S: Association of serum 25-hydroxyvitamin D with type 2 diabetes and markers of insulin resistance in a general older population in Finland. Diabetes Metab Res Rev 2012, 28(5):418-423.

38. Holick MF: High prevalence of vitamin D inadequacy and implications for health. Mayo Clin Proc 2006, 81(3):353-373.

\section{doi:10.1186/1472-6823-13-36}

Cite this article as: Foucan et al:: Polymorphisms in GC and NADSYN1

Genes are associated with vitamin D status and metabolic profile in Non-diabetic adults. BMC Endocrine Disorders 2013 13:36.

\section{Submit your next manuscript to BioMed Central and take full advantage of:}

- Convenient online submission

- Thorough peer review

- No space constraints or color figure charges

- Immediate publication on acceptance

- Inclusion in PubMed, CAS, Scopus and Google Scholar

- Research which is freely available for redistribution 